\title{
Evolution of landform design concepts
}

\author{
E.J. Howard Landloch Pty Ltd, Australia \\ R.J. Loch Landloch Pty Ltd, Australia \\ C.A. Vacher Landloch Pty Ltd, Australia
}

\begin{abstract}
Over the last 10 years, Landloch Pty Ltd has developed and applied a distinctive approach to the design of final waste dump shapes and the management of their rehabilitation. Various elements of that approach have been recommended and/or adopted by both industry and regulators to greater or lesser degrees, and with varying levels of both commitment and success. This paper briefly outlines the approach applied, and discusses its limitations and successes, using examples from a number of mine sites. It then considers alternative approaches to landform design that have been advanced, including use of generic guidelines, attempts to mimic natural landscapes, and attempts to simply mimic advanced design methodologies. Conceptual weaknesses of those alternative approaches are reviewed, and potential for further refinement is discussed, again, using data from various sites.
\end{abstract}

\section{Introduction}

Across Australia, mining regulatory bodies provide guidance on the required state of rehabilitated landforms. For example, Western Australian regulators require safe, stable, non-polluting post-mining landforms, with resilient and self-sustaining vegetation comprised of local provenance species (DoIR, 2001; EPA, 2006). In Queensland, rehabilitated areas are required to be safe for humans and wildlife, non-polluting, stable, and able to sustain an agreed post-mining land use (EPA, 2007). Mining Operations Plans for New South Wales' mines must rehabilitate land such that stable and permanent landforms are created that are suitable for the agreed end land use, that will not adversely affect surrounding land, and with maintenance needs no greater than the surrounding land (NSW DPI, 2006). Other states and territories have similar requirements. Stability of the landform surface and the ability of that surface to support suitable vegetation are obviously key requirements.

In Australia, it has been common practice for regulatory agencies to specify batter angles and flow networks (e.g., level or graded banks, rock drains) that have been widely applied, with little consideration of variations in regional rainfall or in material (waste, topsoil) properties. In Landloch's experience, based on inspection of hundreds of waste dumps, that 'one size fits all' approach has frequently been unsuccessful where unstable materials are used, and typically, results in gullying due to the flow-concentrating drainage pattern created.

To address this problem, over the last 10 years, Landloch Pty Ltd has developed and applied a distinctive approach to the design of landforms and the management of their rehabilitation to address the key requirements of stability and sustainability of vegetation (Loch and Willgoose, 2000; Loch and Vacher, 2006; Loch et al., 2006, 2008; Howard et al., 2010). Landloch has successfully applied this approach to both new landforms and to the remediation of existing landforms constructed using inappropriate designs, with the Landloch designs achieving return of environmental performance bonds in unusually short time periods (e.g. Howard et al., 2010; and advice from Murrin Murrin Nickel Operation).

Other (alternative) approaches to landform design have been used in Australia, with mixed success. The scientific basis (or lack thereof) for those approaches will be discussed in the following sections. 


\section{Landloch's design approach}

Landloch's approach to landform design could be summarised as:

1. Assessment of topsoil and spoil properties.

2. Design and construction of landforms based on material properties.

3. Consideration and avoidance of known 'failure' mechanisms.

Fundamental to this approach is that the properties of the materials stored within the landform and the way these materials interact with the climate, strongly influence the required design. Landforms should be site and material-specific.

\subsection{Material characterisation}

Material properties of importance include:

- Potential for wastes to generate acid, mobilise metals or salts, and/or spontaneously combust

- Basic chemical properties - pH, Electrical Conductivity as a measure of salinity, Exchangeable Cations $\left(\mathrm{Ca}^{2+}, \mathrm{Mg}^{2+}, \mathrm{Na}^{+}, \mathrm{K}^{+}\right)$

- Basic physical properties - particle size distribution, water holding characteristics, dispersion potential, tendency to tunnel, and tendency for surface seals to develop

- Fertility of near-surface materials - macro- and micro-nutrient contents of materials within the active root-zone, with required levels being appropriate for sustainable plant growth and not toxic to vegetation

- Material erodibility - infiltration characteristics, detachment characteristics from rills and interrill areas as a function of energy applied by raindrop impact, shallow distributed surface flows, and concentrated surface flows.

Before considering the stability of near-surface materials, these materials must first be able to support vegetation. They must have suitable $\mathrm{pH}$ and salinity, be able to hold sufficient water within the active root zone, and have suitable fertility. Once it is established that near-surface materials are not likely to cause significant limitations to vegetation establishment and growth, landform stability is considered.

\subsection{Assessment of erosion potential}

Landform stability is primarily related to erosion potential, and its assessment is a vital component of the landform design process. Landloch routinely uses a range of soil erosion models (or components of them) to address different aspects of the design process. Models vary in their structure, their inputs, and the issues they consider. A key task in the design process is to determine the information required and select the most appropriate model. In some cases, a number of models are applied in partnership to consider a wide range of aspects relevant to a particular project.

In general, it is essential that simulations of runoff and erosion are based on local climate, and consider the materials present on-site.

Three main models are employed by Landloch: the Water Erosion Prediction Program (WEPP) model, the SIBERIA landform evolution model, and the Revised Universal Soil Loss Equation (RUSLE). Table 1 outlines the key attributes and differences of these models. All models have been extensively validated, have been shown to provide reasonable predictions, and are all extensively documented in scientific literature (Wischmeier and Smith, 1978; Willgoose et al., 1989, 1991, 2003; Renard et al., 1993; Willgoose and Riley, 1995; Ghidey and Alberts, 1996; Liu et al., 1997; Nearing and Nicks, 1998; Boggs et al., 2000; Tiwari et al., 2000; Hancock et al., 2002; Hancock, 2004; Hancock and Willgoose, 2004; Mengler et al., 2004; Hancock and Turley, 2006).

The WEPP model is a relatively complex, process-based model. It runs on a daily time step and can consider a wide range of site properties. Necessary erodibility parameters can be derived from laboratory or field- 
based measurements. It is typically used to consider slopes as profiles. WEPP explicitly allows for consideration of surface water flow concentration and can predict erosion resulting from both rills and gullies as well as from interrill areas.

The SIBERIA landform evolution model considers erosion and deposition on a three-dimensional digital terrain model. Erosion and deposition are computed annually, with each point on the landform surface being raised or lowered as appropriate. It is particularly useful for identifying landscape features that cause erosion or points on a landform that may become unstable over time. It enables strategic manipulation of the landform shape to eliminate or mitigate the causes of instability. It is used to assess stability over hundreds of years, and is an extremely useful tool for predicting (as far as is currently possible given the level of uncertainty about what the future may hold) the sustainability of a landform in perpetuity.

The RUSLE is an empirical soil loss formula initially derived from experimental data. It is a simple equation that uses an annual time step. The RUSLE cannot consider temporal variations in runoff or erosion potential. This is particularly important given that significant temporal variation in runoff is experienced in most mining regions of Australia. It is, however, useful when considering impacts of surface canopy and contact cover (e.g. standing vegetation, tree debris, and rock) on erosion potential. Also, its use of rainfall erosivity (erosive potential of rainfall) allows for relatively rapid consideration of year-to-year variation in erosion potential for different regions.

Table 1 Attributes of various erosion models

\begin{tabular}{llll}
\hline Attribute & WEPP & SIBERIA & RUSLE \\
\hline $\begin{array}{l}\text { Time step } \\
\begin{array}{l}\text { Slope profiles considered } \\
\text { Consideration of vegetation }\end{array}\end{array}$ & Daily & Annual & Annual \\
$\begin{array}{l}\text { Derivation of parameters from } \\
\text { experimental data }\end{array}$ & Goor & Very complex & Simple \\
$\begin{array}{l}\text { Consideration of sediment } \\
\text { transport }\end{array}$ & Fair & Fair & Good \\
$\begin{array}{l}\text { Consideration of different surface } \\
\text { erosion processes }\end{array}$ & Good & Fair & Difficult \\
$\begin{array}{l}\text { Consideration of tunnel erosion } \\
\text { Prediction of deposition }\end{array}$ & Not available & Fair & Not available \\
Modelled timeframe(s) & Good & Excellent & Not available \\
& $\begin{array}{l}\text { Single events }- \\
\text { years }\end{array}$ & $\begin{array}{l}\text { Years }- \text { hundreds } \\
\text { of years }\end{array}$ & Years \\
\hline
\end{tabular}

\subsection{Applications of the design approach}

The design approach has been used to produce designs and assess stability for landforms in a wide range of environments including tropical, temperate, and arid regions, regions subject to cyclones, and for a wide range of materials, including soils, mineral wastes, mining process wastes, and industrial wastes. It was recently applied to a waste dump on Ramelius Resources' Wattle Dam Project near Kalgoorlie as detailed by Howard et al. (2010). In the case of Wattle Dam, the risks of high levels of erosion leading rehabilitation failure were significantly reduced through implementation of a design based on runoff and erosion modelling. Prior to implementation of the material-specific design, observations of batter slopes confirmed that unacceptably high levels of erosion were occurring and that rehabilitation failure due to erosion was all but guaranteed.

The design process has been shown to produce landforms that erode in accord with predicted erosion rates. A significant benefit of using a daily process-based model (e.g. WEPP) is the ability to compare predicted erosion rates for a period with rates measured on the constructed landform for the same period, i.e. for the same runoff events. For example, for waste landform batters designed by Landloch for Minara Resources' 
Murrin Murrin Operations, DRET (2009) reported that erosion monitoring has shown that actual erosion is consistent with that predicted by the design process. Monitoring of these slopes continues.

\subsection{Limitations}

Limitations to the wide use of the approach are largely related to parameterisation of the models.

Parameterisation of the RUSLE relies on soil characteristics that indicate a material's erodibility rather than actually measuring factors directly related to the erosion process. This introduces a source of error that can only be addressed through collection of time series data for runoff and erosion from a slope constructed using the materials in question. This can lead to significant and unnecessary costs, particularly when the slope constructed proves to be unstable and requires remedial work.

The WEPP model, on the other hand, can be parameterised using data collected through measurements made using laboratory techniques. It does not require slopes to be built, but does require access to considerable quantities of material to perform the laboratory measurements (typically in the order of 1 tonne of material). Where slopes do exist (e.g. on a previously constructed waste landform that is showing signs of instability), field-based measurements taken from appropriate surfaces can also be used.

Consolidation and armouring of soil surfaces are poorly considered in the models available, though they can significantly alter erosion potential. These surfaces are invariably more erosion resistant than unconsolidated and unarmoured surfaces and are currently managed by laboratory assessment of already consolidated and armoured surfaces. However, questions relating to the period over which consolidation and armouring of freshly placed materials occurs remains an unresolved issue.

Parameterisation of the SIBERIA model is complex and has traditionally relied on use of long periods of runoff and erosion data that simply do not exist for most sites. Parameterisation of SIBERIA has been advanced by Landloch in recent times in consultation with the developers of the SIBERIA model by using time series data generated from the WEPP model to generate the required SIBERIA parameters. While parameterisation of the SIBERIA model for specific materials remains complex, it is no longer impossible. This makes the SIBERIA model increasingly useful where the sustainability and longevity of constructed landforms must be considered.

\subsection{Avoidance of known failure mechanisms}

Importantly, landform design should consider what erosion processes are typical of the materials and climate at the site of specific interest. Logically, the subsequent design process should — in a qualitative way — aim to eliminate or minimise the main processes of concern. This is particularly important as some soil processes are poorly addressed or not addressed at all within the available models. For example, tunnel erosion is not expressly considered in any model, and management of tunnel-prone materials must, as a result, focus on elimination of conditions that encourage tunnel erosion. Another significant limitation to the successful implementation of landform designs - while not directly related to the models — is the quality of construction work undertaken. There remains the need for suitably experienced rehabilitation contractors to undertake the work. Unlike earthworks typically carried out on mine sites by operational staff, rehabilitation earthworks require a high degree of precision and skill to form the desired slope and soil profiles. A good landform design can be rapidly undermined if construction quality is poor.

Equally, landform designs that are overly difficult to construct, that require unusually specialised equipment, or that rely on unreasonably high levels of precision may need to be re-considered to ensure that they can be practically achieved.

\section{Alternative approaches}

Several alternative approaches to landform design are currently being utilised.

\subsection{Use of generic guidelines}

Historically (or in some cases currently), regulators have required landforms to be constructed using a standardised batter shape without consideration of the climate, the materials stored in the landform, or 
interactions between the materials and surface water flows. Such designs typically involve adoption of linear batters separated by flat or back-sloping benches designed to capture runoff and reduce erosion potential. Water from the top of the dump is typically conveyed to the toe of the dump using rock drains. In Landloch's experience, where these landforms have been employed on highly erodible materials, the benches have been observed to fill with sediment, overtop and initiate gullies. An extremely high proportion of rock drains have been observed to fail, usually in response to poor design or construction. Construction of benches on materials with low erodibility is typically unnecessary as surface runoff need not be captured and erosion potential is inherently low in any case.

Application of a generic guideline results in suboptimal landforms that are either unlikely to be stable or are unnecessarily costly to rehabilitate. In response to the limited usefulness of generic guidelines, regulators (most notably WA regulators) are now focussing on the rehabilitation objectives that must be achieved rather than stipulating specific landform characteristics.

\subsection{Use of concave profiles without supporting erosion modelling}

Much of the material characterisation undertaken for inclusion in mining proposals or during the operational phase of mining does not appear to impact on the landform design decision-making process. The exception is the characterisation of potentially acid-forming material. Where these materials are encountered, landform designs and mining procedures expressly consider and manage the associated risks.

However, at least partly in response to the success of Landloch's move away from 'traditional' landform shapes, a range of recent proposals and rehabilitation works have simply mimicked Landloch's concave batter profiles without any supporting erodibility measurement or erosion modelling. This is of concern, as although Landloch's design approach demonstrated the considerable benefits of a concave batter profile in certain situations, it also showed that in some situations, concave slopes will:

- provide little reduction in erosion potential or be completely unnecessary

- not reduce erosion potential to acceptable levels and result in an unstable landform.

The Wattle Dam Project waste landform (Howard et al., 2010) provides a useful case study of the potential pitfalls of mimicking the advanced design approach and failing to adequately account for all material properties. For the landform in question, application of a concave design (of any practical shape, let alone the optimal shape described) will not (on its own) reduce erosion potential to an acceptable level. Significant rill and gully erosion were shown to be highly likely, so the design included considerable surface cover using tree debris to ensure that an adequate level of stability was achieved. Further, tunnel erosion was a significant risk for this waste landform, and use of a concave batter profile would only partially mitigate the associated risks. The landform design therefore included amendment of materials, and appropriate management of surface water flows on the top of the landform.

Reshaping the landform and using a concave batter without addressing all the factors relating to stability would - in this case - have provided no additional benefit to the site whilst creating considerable cost.

There is potential that adoption of concave slope profiles without underpinning erodibility measurement and erosion modelling will result in the mining industry adopting these inappropriate designs as a new 'guideline', particularly if these designs - typically outlined in mining proposals — are approved by regulators. The end result would be little advancement in environmental best practice, and little benefit to either mining companies or regulators, as the risk of landform failure and necessary costs of remediation will remain largely unchanged.

\subsection{Designs based on natural landscapes}

\subsubsection{Designs based drainage networks of existing landscapes}

Recently, software utilising fluvial geomorphic processes to design landforms has gained the attention of some of the large mining companies. Landloch has recently completed a research program (Landloch Pty Ltd, 2010) funded by the Australia Coal Association Research Program (ACARP) comparing landform designs developed: 
- using the generic landform guidelines for NSW

- on the basis of runoff and erosion model output

- using dedicated landform design software.

Designs were assessed for the Ashton Coal Project and the Glendell Coal Mine, both in the Hunter Valley in New South Wales. Comparison of the designs was made using SIBERIA. The generic design included $10^{\circ}$ linear batters with some having benches and rock drains and others where these were absent. The runoff and erosion model used in landform design was WEPP, and the dedicated landform design software used was Carlson Natural Regrade with GeoFluv (GeoFluv). GeoFluv - developed largely in North America incorporates information on nearby natural drainage networks, and aims to produce landscapes consistent with these networks. The design is based on existing landforms and attempts to empirically integrate channels and hill slopes into a functional, cohesive landform according to fluvial geomorphic principles.

For the climatic zone considered (the Hunter Valley of New South Wales), the erosion simulations showed that all landform designs would be stable if adequately vegetated, demonstrating that — in some regions achievement of long-term stability is more strongly dependent on soil management to maximise vegetation growth than on landform design. It also demonstrated the value of erosion modelling in setting priorities for rehabilitation planning and works.

The GeoFluv approach was found to be limited by its assumption that the natural landforms used to derive the software's input parameters will have drainage and erosion characteristics identical of those that will develop on waste landforms. Australian soils are ancient compared to those in North America. They are strongly differentiated in terms of landscape location and depth within the profile. Crucially, Australia has the highest proportion of sodic (dispersive) soils in the world, and they are seldom naturally located near the surface or on slopes. The GeoFluv approach did not anticipate the placement of these problematic materials near the surface of constructed waste landforms, and consequently was predicted to produce erosion rates higher than those predicted for slopes designed using a runoff and erosion model and measured material properties. The GeoFluv designs were also relatively complex. Their application to new landforms would not only require the use of skilled rehabilitation operators with GPS enabled equipment for final landform shaping; but the final landform design would also need to be incorporated early into mining operations to minimise reshaping costs (though similar requirements for the waste landform to be formed consistent with the final landform profile should be applied irrespective of the design process to be applied). Importantly, the project showed that where relatively 'natural' and complex landforms are required, Geofluv designs could be refined using three-dimensional erosion model output to reduce their erosion potential. This would potentially overcome the major current limitation to its effective use in Australian conditions.

\subsubsection{Designs based on regional landscape characteristics (Natural analogue approaches)}

Designing landforms using slope profiles borrowed from regional landscape features is also common, and is a simplified version of the GeoFluv approach. An example of this includes the use of mesa-style landforms, where unconsolidated waste materials are reshaped often with a concave batter profile and topsoiled. An additional lift of rocky competent material is then added to the top of the waste dump and left at angle of repose, simulating landscapes commonly observed in the arid zone of Western Australia.

Obviously, reinstatement of landforms of a similar shape to those that exist in the region is desirable. However, as is the case with the other alternative approaches outlined previously, failure to adequately characterise the materials stored in the landform can render slopes constructed using waste materials unstable or unnecessarily costly to build. Many of the mesa-style landforms have relatively unfractured rocky caps and very rocky near-surface materials on the steeply sloping batters that effectively throttle erosion potential. Mesas constructed using fractured rocky caps will have different hydrology to the existing mesas with unfractured caps and will differ in their erosion potential.

It should be noted that use of natural landforms as a basis for design should - logically — consider all aspects of the natural landforms, so that the role of rock or vegetation in achieving erosion stability should be noted and taken into account when developing designs for mine site landforms. 


\section{Conclusions}

Landform design methods have advanced considerably over the last 10 years. It is now possible to use various runoff/erosion models to develop site and material-specific landform designs that are demonstrably stable in the medium to long term, and to consider a wider range of rehabilitation goals. Increasingly, regulators are requiring objective assessments of landform stability over longer time periods. Given the financial and environmental liability that is associated with constructed landforms, such assessments are in the best interests of both regulators and the mining industry.

Although it is widely recognised that successful rehabilitation of waste landforms that store highly variable materials in highly variable climates necessitates the use of material and site specific designs, a range of quite simplistic approaches continues to be applied in an attempt to produce landform designs 'on the cheap'. These range from simple application of concave profiles to mimicking of local landscapes, but all fail to adequately consider the properties of the materials being placed. Logically, that limitation can be expected to greatly increase the potential for such designs to be subject to unexpected and unacceptably high rates of erosion when applied to unstable materials, therefore increasing the probability that such designs will eventually, require costly remediation.

\section{References}

Boggs, G.S., Evans, K.G., Devonport, C.C., Moliere, D.R. and Saynor, M.J. (2000) Assessing catchment-wide miningrelated impacts on sediment movement in the Swift Creek catchment, Northern Territory, Australia, using GIS and landform-evolution modelling techniques, Journal of Environmental Management, Vol. 59, pp. 321-334.

Department of Industry and Resources (DoIR) (2001) Environmental notes on mining, Waste rock dumps, State of Western Australia.

DRET (2009) Evaluating performance: monitoring and auditing, Handbook prepared as part of the Leading Practice Sustainable Development Program for the Mining Industry, Australian Government, Department of Resources, Energy, and Tourism.

Environmental Protection Agency (EPA) (2007) Guideline 18: Rehabilitation requirements for mining projects, State of Queensland.

Environmental Protection Authority (2006) Rehabilitation of terrestrial ecosystems, Guidance for the assessment of environmental factors, Guideance No. 6, State of Western Australia.

Ghidey, F. and Alberts, E.E. (1996) Comparison of measured and WEPP predicted runoff and soil loss for Midwest claypan soil, Transactions of the American Society of Agricultural and Biological Engineers, Vol. 39, pp. 1395-1402.

Hancock, G.R. (2004) The use of landscape evolution models in mining rehabilitation design, Environmental Geology, Vol. 46, pp. 1432-1495.

Hancock, G.R. and Turley, E. (2006) Evaluation of proposed waste rock dump designs using the SIBERIA erosion model, Environmental Geology, Vol. 49, pp. 765-779.

Hancock, G., Willgoose, G.R. and Evans, K.G. (2002) Testing of the SIBERIA landscape evolution model using the Tin Camp Creek, Northern Territory, Australia, field catchment, Earth Surface Processes and Landforms, Vol. 27, pp. 125-143.

Hancock, G.R. and Willgoose, G.R. (2004) An experimental and computer simulation study of erosion on a mine tailings dam wall, Earth Surface Processes and Landforms, Vol. 29, pp. 457-475.

Howard, E., Shemeld, J. and Loch, R. (2010) Ramelius Resources' Wattle Dam Project: Achieving bond reduction through leading practice, Goldfields Environmental Management Group 2010 Workshop.

Landloch Pty Ltd (2010) Final Report - Sustainable landscape design for coal mine rehabilitation, Project No. C18024, Report prepared for the Australian Coal Association Research program (ACARP).

Liu, B.Y., Nearing, M.A., Baffaut, C. and Ascough II, J.C. (1997) The WEPP watershed model: III, Comparisons to measured data from small watersheds: Transactions of the American Society of Agricultural and Biological Engineers, Vol. 40(4), pp. 945-951.

Loch, R.J. and Willgoose, G.R. (2000) Rehabilitated landforms: designing for stability, In 'Environmental standards for the New Millennium', in Proceedings 2000 Workshop on environmental management in arid and semi-arid areas, Goldfields Land Rehabilitation Group, pp. 39-44.

Loch, R.J. and Vacher, C.A. (2006) Assessing and managing erosion risk for constructed landforms on minesites, in Proceedings Goldfields Environmental Management Workshop, Kalgoorlie 2006, Goldfields Environmental Management Group, pp. 121-127.

Loch, R., Stevens, T., Wells, G. and Gerrard, R. (2006) Development of key performance indicators for rehabilitation, Murrin Murrin Operation, in Proceedings First International Seminar on Mine Closure (Mine Closure 2006), 
A.B. Fourie, M. Tibbett (eds), 13-15 September 2006, Perth, Australia, Australian Centre for Geomechanics, Perth, pp. 569-576.

Loch, R.J., Vacher, C.A. and Lowe, S.M. (2008) Topsoil organic carbon and nutrient considerations for waste dump rehabilitation, in Proceedings Goldfields Environmental Management Workshop, 2008, Kalgoorlie, pp. 102-108.

Mengler, F.C., Hancock, G.R., Gilkes, R. and Grant, C. (2004) Managing erosion in rehabilitated bauxite mine soils using the SIBERIA landform evolution model, in 'SuperSoil 2004', Australian Society of Soil Science Inc.

Nearing, M.A. and Nicks, A.D. (1998) Evaluation of the Water Erosion Prediction Project (WEPP) model for hillslopes: in Modelling Soil Erosion by Water, J. Boardman and D.T. Favis-Mortlock (eds), Springer-Verlag NATO-ASI Series I-55, Berlin, pp. 45-56.

New South Wales Department of Primary Industries (NSW DPI) (2006) Guidelines to the mining, rehabilitation and environmental management process, Environmental Management Guidelines for Industry, State of New South Wales.

Renard, K.G., Foster, G.R., Weesies, G.A., McCool, D.K. and Yoder, D.C. (1993) Predicting soil erosion by water: A guide to conservation planning with the revised universal soil loss equation (RUSLE), US Department of Agriculture, Agriculture Handbook No. 703, National Technical Information Service, Springfield, Virginia.

Tiwari, A.K., Risse, L.M. and Nearing, M.A. (2000) Evaluation of WEPP and its comparison with USLE and RUSLE, Transactions of the American Society of Agricultural and Biological Engineers, Vol. 43, pp. 1129-1135.

Willgoose, G.R., Bras, R.L. and Rodrigues-Iturbe, I. (1989) Modelling of the erosional impacts of land use change: A new approach using a physically based catchment evolution model, in Hydrology and Water Resources Symposium 1989, Christchurch, NZ, National Conf. Publ. no 89/19, The Institution of Engineers, Australia, pp. 325-329.

Willgoose, G.R., Bras, R.L. and Rodriguez-Iturbe, I. (1991) A physically-based channel network and catchment evolution model: I Theory, Water Resources Research, Vol. 27, pp. 1671-1684.

Willgoose, G., Hancock, G. and Kuczera, G. (2003) Testing of an erosion-based landform evolution model using objective statistics, Geophysical Research Abstracts, Vol. 5, EAE03-A-11904.

Willgoose, G.R. and Riley, S.R. (1995) Application of a catchment evolution model to the prediction of long term erosion on the spoil heap at Ranger Uranium Mine: Stage 1 report, Open File Rec. 107, Supervising Scientist for the Alligator Rivers Region, Canberra.

Wischmeier, W.H. and Smith, D.D. (1978) Predicting rainfall erosion losses - a guide to conservation planning, US Department of Agriculture, Agriculture Handbook No. 537, US Government Printing Office, Washington, DC. 